\section{PREVALENCE OF AIRWAY OBSTRUCTION AND MASK LEAK DURING FACE MASK VENTILATION OF PRETERM INFANTS IN THE DELIVERY ROOM}

\author{
G.M. Schmölzer ${ }^{1,2,3,4}$, J.A. Dawson ${ }^{1,4,5}$, \\ O.C. Kamlin ${ }^{1}$, C. O’Donnell6, C.J. Morley ${ }^{1,4}$, \\ P.G. Davis ${ }^{1,4,5}$
}

${ }^{1}$ The Royal Women's Hospital, Melbourne, VIC, Australia, ${ }^{2}$ Medical University Graz, Graz, Austria, ${ }^{3}$ Monash Institue of Medical Research, ${ }^{4}$ Murdoch Children Research Institute, ${ }^{5}$ Obstetrics \& Gynaecology, The University of Melbourne, Melbourne, VIC, Australia, ${ }^{6}$ The National Maternity Hospital, Dublin, Ireland

Background: The effectiveness of positive pressure ventilation (PPV) in the delivery room can be impaired by many factors. This study reviewed recordings of neonatal resuscitations at The Royal Women's Hospital, Melbourne, Australia to assess the prevalence of mask leak and airway obstruction.

Methods and patients: Recordings of infants $<32$ weeks gestation born between February 2006 and March 2009 were reviewed. Mask PPV was delivered with a T-piece or self-inflating bag. Airway pressure and gas flow were recorded. A webcam showed the resuscitation. Obstruction was defined as a $75 \%$ reduction in expired tidal volume compared to the 10 previous inflations. Face mask leak was defined as a leak $\geq 75 \%$ of delivered tidal volume.

Results: Recordings from 53 preterm infants were analysed. A median (IQR) of 76 (53 to 98) inflations were analysed for each infant. Obstruction and leak were identified in $14(26 \%)$ and 27 (51\%) respectively. In 8 infants both obstruction and leak were present; in 17 neither occurred. Obstruction occurred at a median (IQR) of $48(24-60)$ seconds after start of PPV. A median (range) of 22 (3 - 83) consecutive obstructed inflations were delivered during each resuscitation. Face mask leak occurred from the first inflation in 19/27. A median (range) of 10 (3-117) consecutive inflations with a leak $\geq 75 \%$ were delivered.

Conclusion: Face mask leak is more common than airway obstruction during neonatal resuscitation. Both may cause a clinically important reduction in the tidal volumes delivered.

\section{SUSTAINED INFLATIONS; COMPARING THREE NEONATAL RESUSCITATION DEVICES}

C. Klingenberg ${ }^{1,2}$, J.A. Dawson ${ }^{2}$, A. Gerber ${ }^{2}$, C.O.F. Kamlin², P.G. Davis ${ }^{2}$, C.J. Morley²

${ }^{1}$ Dept. of Paediatrics, University Hospital of North Norway, Tromsø, Norway, ${ }^{2}$ Newborn Services, Royal Women's Hospital, Melbourne, VIC, Australia

Background and aims: Some national resuscitation guidelines advocate using sustained initial inflations (2-3 sec) for babies requiring resuscitation. Inflation times $\geq 10 \mathrm{sec}$ have been used for preterm infants. Our objective was to evaluate the ability of operators of varying experience to provide a sustained inflation using three different manual ventilation devices.

Methods: We compared a self-inflating bag, a flowinflating bag and a pressure limited T-piece device. Fifty clinical staff from five groups gave a sustained inflation with a target peak pressure of $30 \mathrm{~cm} \mathrm{H}$ and target duration of $10 \mathrm{sec}$ to a leak free manikin. We measured peak inflating pressure (PIP) and mean inflating pressure (MIP) during the sustained inflation, and the duration of inflating pressure (IP) $>20$ and $25 \mathrm{~cm} \mathrm{H}_{2} \mathrm{O}$.

Results: Median (IQR) duration of IP $>25 \mathrm{~cm} \mathrm{H}_{2} \mathrm{O}$ was: flow-inflating bag $10.6 \mathrm{sec}$ (8.4-12.9), T-piece $10.7 \mathrm{sec}(8.9-11.9)$ and self-inflating bag $2.5 \mathrm{sec}$ (0.8-5.7). There was a weak correlation between experience using a self-inflating bag and longer inflation times ( $R$ 0.290, $p=0.041$ ). Compared with the T-piece, the flow-inflating bag had lower mean MIP $\left(27.0 \pm 1.8\right.$ vs. $\left.28.8 \pm 2.0 \mathrm{~cm} \mathrm{H}_{2} \mathrm{O}\right)$ and higher mean PIP $\left(32.3 \pm 3.7\right.$ v. $\left.29.8 \pm 1.8 \mathrm{~cm} \mathrm{H}_{2} \mathrm{O}\right)$. There were no differences in performance between operator groups.

Conclusion: The T-piece provided consistent PIP during one $10 \mathrm{sec}$ sustained inflation with less variation in pressure compared with the flow-inflating bag. Sustained inflations $>3 \mathrm{sec}$ were difficult to achieve with a self-inflating bag. 